\title{
DER JUNGE MOSES HESS IM LICHTE BISHER UNERSCHLOSSENER QUELLEN $^{1}$
}

\author{
I 8 I $2-$ I 835
}

Moses Hess wurde am 21. Januar I 8 I 2 zu Bonn im Hause Nr. 807 in der Judengasse geboren. ${ }^{2}$ Seine Vorfahren lassen sich väterlicherseits bis zu seinem Urgrossvater und mütterlicherseits bis zu seinem Grossvater zurückverfolgen. ${ }^{3}$ Das Geburtsjahr seines Urgrossvaters, David

1 Die in diesem Artikel benutzten Manuskripte und handschriftlichen Briefe von Hess sind zum Teil im Internationalen Institut für Sozialgeschichte (IISG) in Amsterdam und zum Teil im Zionistischen Zentralarchiv in Jerusalem. In meiner soeben erschienenen Arbeit, The Works of Moses Hess; an Inventory of his Signed and Anonymous Publications, Manuscripts, and Correspondence (Leiden, E. J. Brill, 1958), sind sie bibliographisch genau verzeichnet. Das hier öfters angeführte Tagebuch von Hess (Signatur: B I) befindet sich im IISG. Moses Hess' Briefwechsel (hrsg. von E. Silberner, unter Mitwirkung von W. Blumenberg) ist im Drucke; er wird alle hier zitierten Hess-Briefe in extenso enthalten. 2 Laut der Geburtseintragung im Hauptregister des Standesamtes zu Bonn war sein offizieller Vorname: Moises. Er wird auch so in manchen Polizeiakten genannt. „Moritz” ist sein angenommener Name.

${ }^{8}$ Die Angaben über Hess' Vorfahren entnehme ich folgenden Quellen:

A. „Moses Hess. Fragmente zu seinem Lebensbilde. Von Dr. David de Jonge, prakt. Arzt. Köln, I 888." Maschinengeschriebene Abschrift, ı 2 S., fo, etwa 700 Zeilen. David de Jonge (18 5 8-1 188) war Hess' Neffe und wusste wohl alles, was der Familie über Moses bekannt war. Sein Aufsatz behandelt Hess' Leben bis zum Februar 1845. Dann bricht die Abschrift ab; ob das Original weitergeht und bei wem es sich eventuell befindet ist unbekannt. Vermutlich bricht der Bericht ab wegen de Jonge's Erkrankung und frühzeitigen Todes am 2I. September 1888 . Der Aufsatz ist wichtig, muss aber vorsichtig benutzt werden, da er auch einige Ungenauigkeiten enthält. Eine Abschrift des Aufsatzes verdanke ich Herrn Professor Dr. Hans Vogts, Unkel-Scheuren (Rheinland), der ein Exemplar von Baudirektor Behrendt (Gatte von Marie de Jonge, einer Grossnichte von Moses Hess) erhalten hat. Für seine bereitwillige Uberlassung dieses Aufsatzes spreche ich ihm meinen tiefgefühlten Dank aus.

B. „Stammbaum Moses Hess” (2 S., fo), zusammengestellt von seinem Urgrossneffen Herm Otto H. Hess, Berlin-Dahlem, für dessen Mitteilung (1955) ich ihm zu Danke verpflichtet bin.

C. Schriftliche Mitteilungen(1955) von Frau Maria Callmann, Long Island, N.Y., für die ich hier herzlichst danke.

D. Grabinschriften im jüdischen Friedhofe zu Deutz. 
(auch Tebli) Hess ist unbekannt. Er wurde in Abterode, Kr. Eschwege, Hessen-Nassau, geboren, und war Oberrabbiner der Gemeinde Mannheim. In der Rabbinengeschichte des achtzehnten Jahrhunderts ist er eine vielgenannte Persönlichkeit, da er in dem langwierigen Clever Ehescheidungsprozess ( 1766 ) eine wichtige Rolle spielte. ${ }^{1} \mathrm{Er}$ ist im Jahre 1767 in Mannheim gestorben. Sein Sohn Nathan David Hess (geb. $1756^{2}$ in Mannheim) lebte als Kolonialwarenhändler in Bonn, wo er ein ortsansässiges Mädchen, Eva Wetzlar, heiratete. Aus dieser Ehe entsprang David Hess (geb. 1790 in Bonn), der Vater unseres Moses. Er verbrachte seine Jugendjahre in Bonn, wo er am Geschäfte seines Vaters mitarbeitete. Im Jahre 1794 zogen die Franzosen ein, und mit ihrem Erscheinen änderte sich radikal die Stellung der Juden im Rheinlande. Die Franzosen gewährten ihnen vollständige Emanzipation, auch das Recht ausserhalb des Ghettos zu wohnen und Grundbesitz zu erwerben. Deshalb erschienen sie den Juden als ihre Befreier. Die Sympathie der Juden für die Franzosen ist um so verständlicher, als bei der Besitznahme der Rheinlande durch Preussen (I 8 I 5), diese vollständige Emanzipation beträchtlich eingeschränkt wurde. Finanziell ging es der Familie Hess recht kümmerlich, da das Kolonialwarengeschäft durch die Kontinentalsperre litt. Um i 8 ro heiratete der zwanzigjährige David Hess die um vier Jahre ältere Helene (Jeannette) Flörsheim, geboren $\mathbf{1 7 8 6}$ in Bockenheim (bei Frankfurt am Main), wo ihr Vater Moses Flörsheim Rabbiner war. Über ihre ferneren Vorfahren ist nur bekannt, dass sich unter ihnen ein rabbinischer Schriftsteller befand, der aus Polen nach Deutschland flüchtete um seine Frau den Verfolgungen eines Edelmannes zu entziehen. In der Familie lebte der Name des Schriftstellers zwar fort, aber nur, nach alter Tradition, in einer hebräischen Initialform: Moh'rich ${ }^{3}$, die anscheinend nicht mehr zu identifizieren ist. Threm Manne schenkte Helene fünf Kinder: auf den ältesten, Moses Hess, folgten: Lazarus (1 814-1 890), Samuel (I 8 I 7-I 88 I), Julie (auch Gudula) (I 8 20-I 898) und Karoline (I 82 5-I 897 ).

David Hess, Moses' Vater, war ein praktischer und erfolgreicher Kaufman. I 816 oder I 8 I 7 übersiedelte er von Bonn nach Köln, wo er anfangs ein Kolonialwarengeschäft betrieb. Um I 833 gründete er mit einem christlichen Fassbindermeister, Franz Wilhelm Horst ${ }^{4}$, eine

I Carl Brisch, Geschichte der Juden in Köln und Umgebung. Köln, I 882. 2. Band, S. 138.

2 Das Geburtsdatum ergibt sich aus der Angabe in dem Geburtschein von Moses Hess, wonach Nathan David Hess 1812 sechsundfünfzig Jahre alt war. Bei der durch die Franzosen verordneten „Juden-Namen-Annahme” im Jahre 1 808, erklärte er den Familiennamen Hess für sich und seine minorennen Kinder (darunter David) beibehalten (conserver) zu wollen. Cf. Stadtarchiv Bonn, Juden-Namen-Annahme. I 808 . November I 5 .

3 Moses Hess, Rom und Jerusalem, die letzte Nationalitätsfrage. Briefe und Noten. Leipzig, I 862, S. 40, 43.

4 Vgl. Neues Kölncr Adtess-Buch. Köln I844, S. I 86. 
Zuckerraffinerie, die er später allein weiterführte. Als Firma „D. Hess \& Sohn" bestand sie bis I 881, überdauerte ihn also ein Menschenalter. Obwohl er sein Geschäft mit einem nur sehr geringen Kapital begann, verstand er es durch Umsicht und Sparsamkeit zu grosser Wohlhabenheit zu gelangen. Unter den Juden in Köln nahm er eine sehr geachtete Stellung ein; so war er in den vierziger Jahren des vorigen Jahrhunderts Gemeindevorsteher. ${ }^{1}$ Die Zahl der in Köln ansässigen Juden war damals sehr gering. Nach mehr als dreihundertjährigen Verbannung, ermöglichte ihnen erst die französische Invasion sich dort wieder anzusiedeln. Die ersten Juden trafen $179^{8}$ in Köln ein. I 8 I 5 zählte die Stadt nur dreissig jüdische Familien. Daher gab es auch keine besondere Schule für jüdische Kinder. Um ihm eine traditionelle jüdische Erziehung zu ermöglichen, liess man den kleinen Moses - er war kaum fünf oder sechs Jahre alt - in Bonn bei den Grosseltern. Mit Ausnahme von etwa ein bis zwei Jahren ${ }^{2}$ blieb er dort bis 1829 .

Über seine Kindheit liegen keine zeitgenössischen Angaben vor. Das Wenige, was darüber bekannt ist, verdanken wir Hess selbst, der Jahrzehnte später einiges über seine Kindheit veröffentlichte. Hess besuchte keine deutsche Volksschule: zu Hause wurde selbstverständlich Jiddisch gesprochen; sein Deutsch war noch in seinem zwanzigsten Lebensjahre nicht ganz korrekt. Es bestehen auch keine Angaben darüber, ob Hess eine jüdische Schule besuchte. Seine gar nicht geringen Kenntnisse in der hebräischen Sprache und in der Bibel scheint er sich hauptsächlich bei seinem orthodoxen und in der Thora gelehrten Grossvater erworben zu haben. Der Grossvater weihte ihn auch in den jüdischen Kultus ein, der bekannterweise einen durchgreifenden Einfluss auf das häusliche Leben der religiösen Juden ausübt. Vom grosselterlichen Hause stammt seine Liebe zum Heiligen Lande und sein jüdischer Patriotismus im allgemeinen.

So heisst es bei Hess: "Ich erinnere mich nie ohne tiefe Rührung der Szenen, die ich als Kind im Hause meines frommen Grossvaters zu Bonn erlebt habe, wann der Tag der Zerstörung Jerusalems heran nahte. In den ersten neun Tagen des Monats $\mathrm{Ab}$ nahm die schon drei Wochen vor dem verhängnisvollen neunten Tage dieses Monats begonnene Trauer einen recht düstern Charakter an. Selbst der Sabbat verliert in diesen Tagen der tiefsten Nationaltrauer sein heiteres Festgewand und wird sehr bezeichnend der ,schwarze Sabbat' genannt." (Rom und Jerusalem, Leipzig 1862, S. 19).

1 Ibid., Jahrgänge I 84I, I 844, I846, I 849, unter „Hess, David”.

2 Nicht genau feststellbar, etwa in der Periode $1823-1825$. Er verbrachte diese Zeit bei "Onkel und Tante Hess", die sich auch einer Identifizierung entziehen. Vgl. Hess' undatierten Brief (1825?) an seine Eltern, Signatur: C I 22. 
Hess fährt fort: „Mein strenggläubiger Grossvater war einer jener ehrwürdigen Schriftgelehrten, die, ohne ein Metier daraus zu machen, Titel und Kenntnisse eines Rabbiners hatten. Nach beendigtem Tagesgeschäfte studierte er das ganze Jahr hindurch bis nach Mitternacht den Talmud mit seinen vielen Kommentaren. Nur in den ,neun Tagen' wurde dieses Studium unterbrochen. Er las alsdann mit seinen Enkelchen, die bis Mitternacht aufbleiben mussten, die Sagen von der Vertreibung der Juden aus Jerusalem. Der schneeweisse Bart des strengen alten Mannes wurde bei dieser Lektüre von Tränen benetzt; auch wir Kinder konnten uns dabei natürlich nicht des Weinens und Schluchzens enthalten." (Ebenda, S. 19-20).

Diese Erinnerungen schrieb Hess als er go Jahre alt war, also in einem Alter, wo schon das Gedächtnis die in die Vergangenheit projizierten Erlebnisse nicht selten verschönert. Darüber, ob er im grosselterlichen Hause auch Liebe und Verständnis fand, wie er ausserhalb seines frommen Studiums seine Zeit vertrieb, ob die Atmosphäre des streng orthodoxen Heimes ihn nicht bedrückte - über all die kleinen und grossen Ereignisse des täglichen Lebens die den Charakter des Kindes gestalten - darüber finden wir nicht die geringste Andeutung, weder in Hess' Schriften noch in seinem literarischen Nachlass.

Hess unterrichtet uns noch über ein Erlebnis aus seinem zarten Kindesalter. In „Rom und Jerusalem” (S. 39 f.) erzählt er, dass er sich seiner Mutter recht gut erinnere: „ich habe sie zwar als Knabe von vierzehn Jahren verloren, aber sie ist mir noch bis vor kurzem fast jede Nacht im Traume erschienen. Wie von gestern entsinne ich mich noch der Worte, die sie mir einst auf die Seele band, als sie mich in Bonn besuchte. Ich war etwa sieben Jahre alt. Wir lagen schon zu Bett, und ich hatte eben das Nachtgebet beendet. Da hob sie mit bewegter Stimme an: ,Hör, mein Kind, Du musst nur immer fleissig lernen. Moh'rich ist unter meinen Vorfahren, und Du hast Glück, bei Deinem Grossvater zu lernen. Es heisst aber, wo Grossvater und Enkel Thora lernen, da weicht die Gotteslehre nicht mehr von Kind zu Kind.' Die Worte meiner Mutter mussten einen tiefen Eindruck auf mich gemacht haben, da sie mir noch heute erinnerlich sind, obgleich ich seitdem niemals wieder von jener Sage über Grossvater und Enkel etwas gehört oder gelesen habe."

Diese schöne Stelle ist eindrucksvoll, darf aber nicht wörtlich aufgefasst werden. Schrieb doch Hess selbst, als er 24 Jahre alt war, in seinem Tagebuche (2. Januar I 836): „Von meiner Mutter weiss ich wenig mehr, als dass ich ihren Tod bitter beweint habe". Zweifelsohne liebte er innigst seine frühverstorbene Mutter; er muss sie aber ziemlich selten gesehen haben, da er so wenig von ihr weiss.

Sie ist am 28 . Novembe 2 I 825 an einer Lungenentzündung gestorben 
und ruht auf dem jüdischen Friedhofe zu Deutz bei Köln. Mit ihrem Tode ist Hess' Kindheit eigentlich zu Ende. Der Vater nahm den vierzehnjährigen Knaben mit in sein verwaistes Heim nach Köln, um ihn $\mathrm{zu}$ einem tüchtigen Kaufmann und seinem Nachfolger heranzubilden. ${ }^{1}$

Der Kontrast zwischen Vater und Sohn war so gross, dass gegenseitige Sympathie beinahe unmöglich war. Der Vater war ein praktischer Mensch, der Sohn ein Träumer. Beim Vater dominierte der nüchterne Verstand, beim Sohne die Phantasie. Der Vater verfolgte materielle Zwecke, der Sohn suchte nach Idealen. Der Vater dachte in streng-orthodoxen Begriffen, der Sohn - philosophierte. Auch für das Streben des Sohnes nach Kunst und Bildung, hatte der Vater kein Verständnis. Diese Gegensätze wurden eine Zeitlang durch den Gehorsam des Sohnes, auch durch seine religiöse Zucht, gelindert. Der Junge gab sich grosse Mühe den schon damals lungenleidenden und asthmatischen Vater nicht zu kränken. Typisch in diesem Zusammenhange ist zum Beispiel ein Satz aus seinem Briefe von April 183 I an einen Jugendfreund, M. Levy: „Das Theater besuch' ich selten, selbst wenn ich ein grosser Liebhaber davon wäre, würde ich's jetzt nicht gut tun können, indem mein Vater es sehr ungern sieht, und es doch Pflicht ist, auch den Vorurteilen der Eltern zu huldigen, insofern sie nicht mit böbern Pflichten in Widerspruch stehn." Auf die Dauer mussten freilich diese latenten Gegensätze zu offenen Konflikten führen. Sie brachen auch tatsächlich in naher Zukunft aus. Doch darüber, später.

Hess' Freundeskreis in jener Zeit war ziemlich klein. In dem soeben angeführten Brief an Levy berichtete Hess, dass er wenig Freunde habe: „Hier [in Köln] habe ich einen, nebst meinem Bruder, auswärts zwei, einen davon kennst Du nicht, [er] war einige Jahre hier, mit dem andern meine ich meinen lieben Zuntz ${ }^{2}$, letzterer besitzt mein ganzes Vertrauen, mit beiden steh' ich im Briefwechsel". Es ist nicht schwer zu erraten, wer die nicht mit Namen genannten Freunde waren. Der an erster Stelle angeführte dürfte wohl kein anderer als Hermann Levié sein. Von Hess' zwei Brüdern, die siebzehn respektive vierzehn Jahre alt waren, war nur der ältere, Lazarus, reif genug um als „Freund” bezeichnet zu werden. Der dem M. Levy unbekannte, auswärtige Freund, war vermutlich ein junger Holländer in Amsterdam; er ist uns aus dem Hess'schen Briefwechsel nur unter seinen

1 David de Jonge, „Moses Hess”, S. 4.

2 Leopold Zuntz ist nach Auskunft des Bonner Standesamtes am 13. Juni 1874 im Alter von 66 Jahren in Bonn verstorben. 
Initialen - I.K. - bekannt. Über den Briefempfänger selbst, M. Levy, mit dem ja Hess auch befreundet war, konnte nichts Näheres in Erfahrung gebracht werden. Leopold Zuntz war der einzige Sohn von Moses' Tante, Recha Hess, die mit Anselm Zuntz verheiratet war, und dessen Kolonialwarenhandlung sie nach seinem Tode unter der Firma „Anselm Zuntz sel. Witwe” weiterführte. Leopold Zuntz war später Teilhaber dieser Firma und Mühlenbesitzer. Als Knaben in Bonn waren Moses und Leopold schon befreundet. Leopold Zuntz war jahrelang der intimste Freund von Hess, und zeigte auch für dessen philosophische Bestrebungen Teilnahme und Verständnis.

Hess' interessante Freundschaft mit dem bekannten Schriftsteller Berthold Auerbach ist etwas späteren Datums. Auf Grund der literarischen Nachlässe von Hess und Auerbach ist es kaum möglich genau festzustellen wann sich die beiden kennenlernten. Aus einer Eintragung in Hess' Tagebuch vom 24. Februar I 835 ist jedoch ersichtlich, dass sie schon im Frühjahr 1835 in Briefwechsel standen.

„Unter Hess' Freundschaften”, schreibt David de Jonge in seinen Aufzeichnungen über Hess' Leben, ,ist die mit Hermann Levié, der fast gleichalterig war, und schon früh durch allerhand Kommissionen seinen Lebensunterhalt selbst verdiente, durch ihre Dauer bis an sein Lebensende wie durch ihre Innigkeit hervorzuheben; doch war Levié eine ganz anders angelegte Natur - neben Moses-Don Quichote der echte Sancho Pansa. Aber Moses' Einführung ins Leben besorgte dieser lebenslustige Bursche, und gar manche Gestalten aus niederer Lebenssphäre hat er durch ihn kennen gelernt. Dagegen war Vetter Zuntz, der bald auch zum Oheim [David Hess] in die Lehre kam, der Freund, dem alle neuen Gedanken und Pläne mitgeteilt wurden, der mit ihm in und nach den Geschäftsstunden Rousseau und Spinoza studierte."

Hess besuchte weder ein Gymnasium noch eine Universität. Da er es selbst ausdrücklich festgestellt hat, kann darüber kein Zweifel bestehen. ${ }^{1}$ Er war Autodidakt im wahrsten Sinne des Wortes. Er half dem Vater in seiner Kolonialwarenhandlung, das Geschäft liess ihm aber genug Musse um sich - wie er sagt - mit dem Nötigsten und Nützlichsten für's Leben, vertraut zu machen. ${ }^{2}$ Mit Mühe erwarb er sich immer grössere Kenntnisse der deutschen Sprache. Er machte

1 Hess, Tagebuch, 18 . Januar I 836 . Hess besuchte also nicht die Bonner Universität, wie es de Jonge („Moses Hess”), Carl Hirsch (in: „Der arme Konrad”, Leipzig, Jahrg. 1876, S. 68) und der „Kölner [Polizei-] Wochenbericht” vom 28. März 1852 (Ehem. Preuss. Geh. Staatsarchiv) behaupten. In dem Immatrikulations-Manual der Bonner Universität vom Jahre 1827 (Nr. 226) ist zwar ein Moises Hess eingetragen, es ist aber nicht unser Moses, sondern ein gewisser Moises Henoch Hess aus Trier.

2 Hess an M. Levy, April I 83 I. 
grosse Fortschritte im Französischen. Er scheint auch Geschichte gelernt zu haben. In der Mathematik hatte er aber beinahe keine Vorbildung. Griechisch blieb ihm ganz fremd, vom Lateinischen kannte er höchstens nur Elemente. Er las viel, wenn auch unsystematisch. „Mit Ehrfurcht”, bemerkt er, „lernte ich nennen, die Namen eines Rambam, eines Rousseau und mancher Deutschen," ${ }^{1}$ die er leider nicht namentlich aufzählt.

Moses Hess stammte aus einer orthodoxen Familie und war auch selbst in seinen jüngsten Jahren ein strenggläubiget Jude, der die Religionsgebräuche genau beachtete. Eine innere Wendung tritt bei ihm um das sechzehnte Lebensjahr ein. Die erste geistige Krisis, die er erlebte und die zu seiner Trennung vom orthodoxen Judentum führte, beschrieb er 1831 in rührenden Worten. „Nachdem ich, ich weiss nicht mehr wieviel, gelesen und erfahren habe, gab's eine ungeheure Revolution in meinem Innern, sie mochte wohl zusammen genommen zwei Jahre gewütet haben, ich litt in dieser Zeit, auf vielfältige Weise konnte ich ihr Opfer werden, der Kampf war hartnäckig, immer neue Gefahren, immer neue Ressourcen, endlich siegte... die Freiheit, die natürliche, die wahre! Es ist nunmehr schon lange her; seit der Zeit genoss ich, Gott sei Dank! einen ungestörten Frieden." 2

Als Ergebnis dieser inneren Kämpfe löste sich Hess vom orthodoxen Judentum. Auf die drängende Frage eines Freundes, ob er recht fromm sei, antwortet er, dass es darauf ankomme, was man unter Frömmigkeit verstehe. Wenn das eifrigste Bestreben ein gottgefälliges Leben zu führen, Frömmigkeit genannt werde, dann sagt Hess, könne sein Gewissen diese Frage bejahen. „Wenn Du aber unter fromm nur den frommen Juden verstehst, so kann ich Dir Deine Frage nicht unbedingt bejahen; wohl bin ich ein echter frommer Jude, aber nur insofern als ich ein frommer Mensch bin, wo jener in Widerspruch mit diesem kommt, da bin ich Mensch auf Kosten des Juden." 3 Obschon er den Glauben hat an die unbedingte Göttlichkeit der Gesetze der Israeliten, solange sie noch eine Nation waren und in einem Lande lebten, so glaubt er doch, dass diese unbedingte Göttlichkeit verloren gegangen sei, nachdem sie aufgehört hätten eine Nation zu sein, Bewohner vieler Länder und Brüder vieler Nationen geworden seien. Er behauptet, dass ebenso wie es schändlich und lächerlich für die Juden, als sie noch in einem Lande vereint waren, gewesen sein würde, ihre Gebote zu übertreten und fremden Göttern zu huldigen, ebenso schändlich und lächerlich sei es, die Gesetze des Landes, in dem sie

1 Ibid.

2 Ibid.

3 Ibid. 
wohnen, gewissenlos zu übertreten und die veralteten Gesetze eines längst zerfallenen Staates mit abgöttischer Verehrung anzubeten. Was zeugt von der Göttlichkeit ihrer alten Gesetze? Dass ihnen die ewigen Wahrheiten zu Grunde liegen, weislich nach Zeit und Ort modifiziert. Die Gesetze müssten also mit Zeit und Umständen stets in Einklang gebracht werden. Die Juden aber befolgen starr ihre alten Gesetze. Sie beten die alte Eiche an, um die Wurzel sind sie unbekümmert. „Die Wurzel hat längst der Wurm zerfressen, der Baum trägt keine Früchte mehr, er steht nur noch da aus alter Gewohnheit, bald, bald wird er ganz zusammenstürzen; so geht's wenn man die Lebensquelle vernachlässigt, und sich an die tote Masse hält; oh! auch ich bin ein Verehrer unserer alten Religion, aber gerade deswegen möchte ich sie, um alles in der Welt gepflegt wissen!" 1

Der junge Hess war kein Atheist, oder um uns genauer auszudrücken, er war es nur kurze Zeit. Im Mai I 829 schrieb er an Zuntz: „Ganz reine Begriffe von der Gottheit und atheistische Begriffe sind so sehr mit einander verwebt, dass es fast unmöglich ist zu jenen zu gelangen, ohne erst diese zu übersteigen. Ja, mein Lieber, ich selbst wurde einst ein Atheist durch mein tiefes Denken - tieferes Denken rettete mich."

Die Weltordnung - das Universum - erscheint Hess als höchst gerecht und gut. Es liege ihr überall der Charakter einer höchsten Vernunft zu Grunde. Ist aber die Weltordnung eine höchst gerechte, so sei sie auch notwendig die allerbeste. Wenn aber Alles das Werk eines höchst vernünftigen, mächtigen und wohltätigen Wesens sei, woher komme denn das Übel auf der Erde? Die Lösung dieses Rätsels findet Hess bei Rousseau. Was ist „das Übel” an sich selbst? Was ist „das Übel" in Beziehung auf die Natur und ihren Urheber? Ordnung herrsche und erfülle sich im Weltall; alles vergehe, denn so sei das Gesetz sinnlicher und empfindender Wesen. Aber alles erneuere sich im Weltall und nichts werde vernichtet, denn so sei die Ordnung seines Urhebers und diese Ordnung widerspreche sich nie. In all dem sieht Rousseau kein Übel. Wenn aber der Mensch leidet, wenn er stirbt, ist es kein Úbel? Sachte, meint Rousseau; der Mensch sei dem Tode unterworfen, weil er das Leben empfangen habe. Es gebe für den Menschen nur ein Mittel nicht zu sterben, nämlich nicht auf die Welt zu kommen. Das Leben sei ein positives Gut, aber endlich: das Ende sei der Tod. Das Ende des Positiven sei nicht das Negative, es sei Null. Der Tod erscheine uns schrecklich, und diesen Schrecken nennen wir ein Übel. Der Schmerz wiederum, sei ein Übel für denjenigen, der leidet. Rousseau gibt das zu. Aber Schmerz und Vergnü-

1 Ibid. 
gen seien die einzigen Mittel ein empfindendes und vergängliches Wesen an seine eigene Erhaltung zu binden, und diese Mittel seien mit einer Güte verwendet, die des höchstens Wesens würdig sei. Das schnelle Aufhören eines beissenden Schmerzes sei ein intensives Vergnügen. Niemand wird jedoch behaupten, dass das Aufhören dieses Vergnügens ein Schmerz sei. Der sanfte Genuss des Lebens sei fortdauernd; um ihn zu kosten, sei es hinreichend nicht zu leiden. Der Schmerz sei nur eine beschwerliche, aber notwendige Ankündigung, dass dies so teuere Gut in Gefahr sei. Betrachtet man dies alles, so findet man, dass in der Ordnung der Natur, das Gefühl des Todes und das des Schmerzes beinahe nichtig sei. Die Menschen seien es, die es verschärft hätten. Ohne ihr unsinniges Raffinement, ohne ihre barbarische Institutionen, würden uns die physischen Übel wenig treffen, wenig rühren, und wir würden den Tod durchaus nicht fühlen. Auch das moralische Übel sei nur ein Werk des Menschen, woran Gott keinen anderen Anteil habe als den Menschen frei und hierin sich gleich geschaffen zu haben. Muss man sich denn wegen der Verbrechen der Menschen und der Übel, die sie sich zuziehen, an Gott halten? Muss man es ihm beim Anblicke eines Schlachtfeldes vorwerfen, so viele zerbrochene Arme und Beine erschaffen zu haben? Wozu, wird man sagen, den Mensch frei schaffen, da er seine Freiheit missbrauche? Weil ein einziger sterblicher Mensch, der sie nicht missbraucht, die Menschheit mehr ehrt, als alle Schurken, welche die Welt bedecken, sie entwürdigen. ${ }^{1}$

Mit allen diesen Gedanken Rousseaus ist Hess vollkommen einverstanden. Er sieht auch keine Veranlassung um grundsätzlich unzufrieden zu sein. „Ich," sagt er 1830, „und ein jeder, der nicht schon moralisch verdorben ist, kann nicht anders als zufrieden in einer Welt leben, in der er voll Vertrauen ausrufen kann: Unrecht geschieht mir nicht! Wenn ich mir nicht selbst wahre Übel zuziehe, so gibt's notwendig durchaus keine solchen für mich; welche Bewandtnis es auch mit ihnen hat, so können sie doch notwendig keine wabren Übel sein; das würde ein Widerspruch sein! Sie müssen, auf welche Art und Weise auch, notwendig eine grössere Summe von Vorteilen haben, so wenig und so selten ich diese auch bemerke; denn - bemerken wir denn einmal unsre Güter, diese geniessen wir stillschweigend; nur ihre Beraubung bemerken wir." 2

Vernunft, meint Hess, sage uns nicht allein was gut und was böse sei; sie lehre uns auch Moral als das höchste Gut zu schätzen. Sittlichkeit ist für Hess einzig und allein die grosse Zentralkraft, um die

1 Rousseau, Oeuvres complètes, Basel, I 793, t. 25 (Pièces diverses, t. I), S. I 50-I 52 , Brief an $M^{* * *}$ vom 15. Januar 1769 ; Hess, Manuskript B I1, geschrieben etwa I830, S. I-s. ${ }^{2}$ Hess an einen Unbekanten (I.K.), 3. Februar $183^{\circ}$ 
sich alles andre dreht. Es sei zwar vernünftig nach Glückseligkeit zu streben, doch müsse man sie der Tugend unterordnen. ${ }^{1}$ Man müsse dabei dem, dem Menschen von Gott eingeflössten, Moralinstinkt folgen, und sogar die kleinsten unmoralischen Handlungen meiden. ${ }^{2}$

Die Behauptung, dass der Mensch ein Produkt der menschlichen Gesellschaft sei, ist für Hess kein Argument gegen die Existenz einer höchst gütigen und höchst gerechten Weltordnung, denn die Gesellschaft selbst ist ein Teil dieser Ordnung. Mit grösster Genugtung zitiert er eine Stelle aus Mendelssohns Phädon, wo Sokrates spricht: „Das menschliche Geschlecht ist zur Geselligkeit so wie jedes Glied zur Glückseligkeit berufen. Alles, was auf eine allgemeine, sichere und beständige Weise zu diesem Endzwecke führen kann, ist unstreitig von dem weisesten Urheber aller Dinge als ein Mittel gewählt und hervorgebracht worden. Diese schmeichelhaften Vorstellungen haben ungemein viel Tröstliches, und zeigen uns das Verhältnis zwischen dem Schöpfer und dem Menschen in dem erquickendsten Lichte."3 Göttlich nennt Hess den hier ausgesprochenen Gedanken. ${ }^{4}$

Materialismus und Utilitarismus lassen Hess kalt. Über Holbach und Helvetius sagt er, dass ihre Werke auf ihn nicht den geringsten Eindruck ausüben könnten, da sie zum grössten Teil voller Vorurteile seien, und das Wenige, das wahr darin sei, werde zu einseitig aufgefasst. Beide führen einen Krieg gegen Schwärmer, und wenn auch die Wagschale ganz auf ihrer Seite herunterschlüge, so hätten sie allenfalls den Sieg über Fanatiker, aber nicht über rein Aufgeklärte davongetragen. Zu allen Zeiten sei es das Unglück der Menschen in Extreme zu verfallen. Religion arte in Schwärmerei, vorurteilsfreie Philosophie in Atheismus aus. Der religiöse Schwärmer verachte alles Profane, der Atheist verspotte alles Religiöse. So ginge es zu allen Zeiten, und so, meint Hess, werde es zu allen Zeiten gehen: überall, von beiden Seiten Extreme! Die Wahrheit liege aber in der Mitte. ${ }^{5}$

Überhaupt entstünden alle menschlichen Irrtümer nicht so sehr durch im eigentlichen Sinne falsche Ansichten, als vielmehr durch zu einseitige oder sogenannte scbiefe Einsichten. Wer neue Systeme zu errichten gedenke, solle sich es doch angelegen sein lassen zu prüfen, ob und inwiefern sich das Neue, welches er biete, mit dem Alten versöhnen lasse. Oft würden neue Systeme mehr durch Ehrgeiz und Originalitätssucht als durch reine Wahrheitsliebe produziert. ,Wenn wir nicht die Systeme, sondern ihte Irrtümer bekämpfen wollten, wenn

1 Hess, Manuskript B I 2, geschrieben etwa I830, S. 5, 7, 9.

2 Hess an Leopold Zuntz, Mai 1829.

3 Moses Mendelssohn, Ges. Schriften, Bd. III/r, Berlin, r932, S. 88.

4 Hess an einen Unbekannten(I.K.), 3. Februar I 830.

5 Hess an einen Unbekannten(I.K.), Juli 1830. 
wir nicht neue Systeme errichten, sondern den wahren Seiten der alten Gerechtigkeit widerfahren lassen wollten, so würden wir die gesegnete Mittelstrasse überall, so würden wir die Wahrheit, die geläuterte und reine, auffinden!" 1

Dies schrieb Hess im August 1830 . Auf der Suche nach jener Wahrheit setzt er seine Studien weiter fort. Im Frühling des folgenden Jahres berichtet er, dass er zwar nicht viel, aber mannigfaltig und mit Wahl lese. ${ }^{2}$ Die in seinem literarischen Nachlasse erhaltenen Notizen und Exzerpte deuten tatsächlich auf eine bunte und ausgebreitete Lektüre. Er las La Bruyère, Wieland und Goethe, und exzerpierte, oft sehr kurz, ausser den schon oben genannten Werken, Rousseau („Emile”), Mendelssohn („Philosophische Gespräche”), Herder(„Ideen zur Philosophie der Geschichte der Menschheit”), Mme de Staël („De l'Allemagne”), Karl von Rotteck („Allgemeine Geschichte”) und die weniger bekannte geistreiche französische Schriftstellerin, Mme de Puisieux (,Caractères”). ${ }^{3}$

Am weinigsten scheint ihn zu jener Zeit die Politik interessiert zu haben. Die Juli-Revolution (1830) machte auf ihn keinen besonders starken Eindruck. Revolutionen, schreibt er im November I 83 I, sind sozusagen Mode geworden. Thre Folgen lassen sich nicht leicht berechnen; im Augenblick wirken sie nur nachteilig; soviel ist indes sicher, dass der monarchische Übermut ein wenig durch sie gezügelt wird. Die Revolutionen erinnern die Monarchen an ihre wahre Stellung in der Gesellschaft und an ihre Pflichten ihr gegenüber. Dieser Vorteil allein wiegt schon vielleicht die momentanen Nachteile der Revolution auf. Was übrigens den eigentlichen Zweck der Revolution, die Freiheit, betreffe, so glaubt Hess, dass "die wahrste und schönste Freiheit in einer echt konstitutionellen Monarchie zu finden sei." 4 Damit hat der achtzehnjährige Hess sich selbst politisch treffend gekennzeichnet. Er ist weder vom sozialen noch vom politischen Standpunkte aus radikal gesinnt: er ist gemässigter, konstitutioneller Monarchist.

Im Alter von neunzehn Jahren hatte Hess noch keine festen Berufspläne. Im April i 83 I weiss er noch nicht, ob er im Geschäfte des Vaters bleiben werde. ${ }^{5} \mathrm{Da}$ ihm jedoch das Geschäft nicht wenig

1 Hess, Manusktipt B 17 , geschrieben im August 1830, S. 5. Vgl. auch S. I-4.

2 Hess an M. Levy, April i 831.

3 Vgl. Hess, Manuskripte B I I, I 2, 18.

4 Hess an einen Unbekannten (I.K.), November 1830 .

5 Hess an M. Levy, April I8zi. 
freie Zeit übrigliess, so hat ihn anscheinend die Frage der Berufswahl damals nicht besonders stark beschäftigt. Die Beziehungen zwischen Vater und Sohn waren erträglich und scheinen anfänglich sogar recht gut gewesen zu sein. Sie verschlimmerten sich jedoch merklich um das Frühjahr I 833. Die Familientradition berichtet, dass es zu jener Zeit zu einem ernsten Konflikt zwischen den beiden gekommen sei. Offenbar hatte Moses selbst dazu Anlass gegeben. Er verliebte sich in ein hübsches jüdisches Dienstmädchen, die „rote Lena”. Sie diente in Bonn bei den mit den Hess befreundeten Wallichs, einer sehr bekannten jüdischen Familie. Moses liess es nicht bei einer gewöhnlichen „Poussage” bewenden, sondern fasste diese Liebesangelegenheit sehr ernst auf. Er hielt das Mädchen, wie man aus einer späteren Bemerkung schliessen kann, ${ }^{1}$ für ein unglückliches weibliches Wesen. Selbstverständlich wusste er, dass sein gutbürgerlicher Vater nie zu seiner Heirat mit einer Magd zustimmen werde. Daher beschloss er ins Ausland zu reisen, sich dort irgendwo literarisch zu betätigen, und seine Geliebte nachkommen zu lassen. Das wenige Geld, welches er hatte, genügte nicht zur Ausführung seines Planes. Um sich Existenzmittel für eine längere Zeit zu sichern, verkaufte er aus der väterlichen Kolonialwarenhandlung, ohne Wissen des Vaters, eine grössere Kaffeesendung, die jedoch nicht sofort bezahlt wurde. Moses begab sich indes nach Holland und es wurde verabredet, dass ihm seine Freunde Zuntz und Levié das Geld nachsenden sollten. Ihr Geldbrief war aber so mangelhaft adressiert, dass er, ohne Moses zu erreichen, nach Köln zurückgeschickt wurde, und dort vom Postamt, da der Name Hess daraufstand, dem Vater ausgehändigt wurde. Der Vater, dem das rätselhafte Verschwinden seines Sohnes recht herben Kummer bereitet hatte, erhielt nun Klarheit über Moses' Vorhaben. Auch Lena, nachdem sie von seinen Geldschwierigkeiten erfuhr, hatte keine Lust ihrem Geliebten zu folgen. Seine Mittel waren schnell gänzlich erschöpft, und er entschloss sich aus Holland - vielleicht aber war er damals schon in Paris - zu den mütterlichen Verwandten in Frankfurt am Main Zuflucht zu nehmen. Bei seiner Ankunft sah er ganz verkommen, gleich einem Bettler aus. Sein Oheim Adler, der Schwager seiner verstorbenen Mutter, nahm ihn gut auf, kleidete ihn neu ein und verpflegte ihn aufs beste. Vor allem sorgten aber die Verwandten für eine baldige Aussöhnung mit dem Vater. Diese bot keinerlei Schwierigkeit, da der Sohn sich bereit erklärte, wieder im väterlichen Geschäfte fleissig zu arbeiten. Moses fand die herzlichste Aufnahme im Vaterhause, vermutlich in der ersten Hälfte I 834 . Soviel

1 Hess, Rom und Jerusalem, S. 2. 
erfahren wir über Moses' erste Liebesangelegenheit und erste „Walze”, aus den Aufzeichnungen seines Neffen, de Jonge. ${ }^{1}$

Von Hess selbst besitzen wir Kunde nur über die Nachklänge der Affäre. Interessanterweise ist sie der Gegenstand der ersten Eintragung in sein Tagebuch (I. Januar I835): „Im letzt vergangenen Monat kam ein Brief von L[ena] an Hermann [Levié], worin erstere ihr trauriges Schicksal beschreibt, und worauf ich nach vielem hin und her Erwägen [...] beschloss, bei meiner Familie und im allgemeinen dahin $\mathrm{zu}$ wirken, dass sie eine ordentliche Heirat eingehe, welches umso ratsamer ist, da sie selbst den Wunsch zu heiraten in jenem Briefe lebhaft geäussert." Hess findet es auch nötig Lenas Familie zu unterstützen. Unter dem 7. Mai I 835 ist nochmals die Rede von einem Briefe Lenas an Levié: sie ,meldet ihre Hochzeit an und lässt sich dann wieder, wie gewöhnlich, über unser früheres Verhältnis aus. - Ich hoffe indessen, dass sie in der Ehe zufrieden gestellt werden wird, da ihr Bräutigam sie wirklich zu lieben scheint." Zu ihrer Hochzeit im Juli I 835 erhielt sie von Hess, Levié und Zuntz ,eine Haussteuer von Gebild und Leinen, zusammen stark ro Thaler" wert. ${ }^{2}$ Abschliessend bemerkt Hess am 20. Oktober 1835 in seinem Tagebuch: „Ich werde schwerlich noch eine Frau finden, die meiner Individualität mehr zusagt, als L. - Aber L's Bildung wurde vernachlässigt und darum könnte sie mich nicht ganz befriedigen."

Diese Liebesaffaire und die damit zusammenhängenden Abenteuer, sowie der durch ihn selbst verursachte - wenn auch vorübergehende Bruch mit dem Vater, erschütterten Hess' Gemütszustand aut's tiefste. Er fühlte sich schuldig, weil er die sittlichen Regeln - die er bisher so streng beobachtete - übertreten hatte und bereute sein überspanntes Handeln. Er war glücklich, dass er seine Zweifel überwunden und seine Leidenschaften bezwungen hatte. Er erlebte nochmals eine Zeit tiefster Gläubigkeit. Endlich hat er den inneren Frieden aufgefunden. „Guter Gott!” schreibt er am I 8 . Februar I 835 in seinem Tagebuche, „so hast Du mich doch nicht verlassen, mir beigestanden und mich gerettet, als die Not schon sehr, sehr gross war! Oh, jetzt will ich Dich auch nie mehr versuchen, will mich nicht mehr von Dir entfernen, denn ich sah schon den offenen Abgrund der Hölle vor mir. Ich bin endlich wieder ausgesöhnt mit Dir und Deiner Welt und kein

1 David de Jonge, „Moses Hess”, S. 5-7. Nach Karl Hirschs (heute unverifizierbaren und wohl von Sibylle Hess stammenden) Angaben ging Hess zuerst nach England um sich eine Existenz zu suchen, und von dort nach vergeblichen Bemühungen nach Paris, wo er auf's kümmerlichste lebte. Dann beschloss er zu Fuss nach Deutschland zurückzuwandern. Er kam aber nur bis zu einem Dorfe in der Nähe von Metz, wo er eine Zeitlang als Lehrer verblieb. Nach einem Jahre söhnte er sich mit seinem Vater aus.

2 Hess, Tagebuch, 9. Juli 1835 . 
Teufel wird mich nun wieder zu entzweien imstande sein." Seit die Hydra der Leidenschaft ihn mit ihren tausend Armen erfasst und hingerissen habe, sei er nicht zu sich selbst gekommen. Jeder Fehltritt habe unzählige Folgen, und jede üble Folge habe wiederum tausend andre nach sich gezogen bis ins Unendliche. Solange er bloss Gutes geübt habe, gesteht er, sei er selig gewesen; als er aber alles habe wissen wollen, habe ihn der Lebenswirbel erfasst und tausend Gefahren hätten ihm den Untergang gedroht. „Die Gefahren sind endlich vorüber - ich habe gewonnen! Vor Deine Füsse, o Gott, werfe ich mich und danke Dir und will Dich ewig anbeten!"

Hess' Tagebuch von 1835 bietet uns einen unmittelbaren Einblick in sein äusseres und inneres Leben. Im Laufe dieses Jahres verstärkte sich die Spannung zwischen ihm und dem Vater. Diesen ärgerte es, dass der Sohn die jüdischen Festtage nicht beobachtete. Es kränkte ihn z.B., dass er gerade am neunten Tage des Monats Ab, dem grössten israelitischen Trauertage, eine Vergnügungsreise unternahm. Ob er wusste, dass sein Sohn I 834 einer Weihnachtspredigt beiwohnte, ist uns unbekannt. Er war unzufrieden mit einigen Freunden des Sohnes, die er seines Verkehrs für unwürdig hielt. Als er zufällig erfuhr, dass sich sein Sohn sein „Reisepatent” erneuern liess, verwies er es ihm. Schliesslich kam es auch zu Konflikten, weil der Sohn glaubte der Vater halte ihn zu kurz. Moses scheint beinahe nie bei Kasse gewesen zu sein und sah sich oft gezwungen Anleihen aufzunehmen. Er klagte darüber, dass ihm der Vater sogar die Mittel verweigere um sich wichtige Bücher anzuschaffen. ${ }^{1}$

Um diesem unerträglichen Zustand ein Ende zu bereiten, plante Hess sich als Kaufmann nach und nach vom Vater finanziell unabhängig zu machen. Er gesteht ausdrücklich, dass die Ursache seiner Unlust in der Familienunternehmung zu arbeiten, nicht in seiner Abneigung gegen den Handel als solchen, sondern in der ihm „nicht zusagenden Persönlichkeit" seines Vaters und Bruders zu suchen sei. ${ }^{2}$ Als Vorstufe zur Unabhängigkeit beabsichtigte Hess, zusammen mit seinem Freunde Zuntz, die Leitung des väterlichen Kolonialwarengeschäfts zu übernehmen, das seiner Meinung nach ohnedies eingehen würde. Hier, dachte er, könne er sich am besten ausbilden für das Geschäftsleben, zu dem er doch einmahl, während einer langen Periode seines Lebens bestimmt sei. Dabei käme er mit Vater und Bruder weniger in Berührung als in jeder anderen Geschäftsverbindung. Der Beistand des Vaters würde ihm am Anfang nützlich sein, und in dem Grade, in dem er ihn nicht mehr bedürfe, müsse seine Unabhängigkeit zunehmen. Da zudem seine eigene Existenz, so wenig wie die der

1 Tagebuch, fo 2, 23, 33, 38a, 48a, 95a, II I.

2 Ebenda, fo ro. 
ganzen Familie, von dem Kolonialgeschäft abhinge - die Haupteinnahmen flossen aus der Zuckerraffinerie, in der auch der Vater hauptsächlich arbeitete - so bliebe ihm in diesem Berufszweig noch genug Zeit und Geistesfreiheit, um seine Ausbildung nicht zu vernachlässigen. ${ }^{1}$ Sollte er Erfolg haben, so könnte er nachher noch eine Fabrik anlegen. ${ }^{2}$ Das Unternehmen kam nicht zur Ausführung, offenbar weil der Vater dagegen war. Auch Zuntz, dessen Mutter gegen seine Assoziation mit Hess war ${ }^{3}$, scheint nicht allzu sehr begeistert gewesen zu sein.

Nun hatte Hess noch einen anderen Plan, über den er in seinem Tagebuch (4. Mai 1 835) berichtet: „Der gänzliche Mangel an Geld in meinen Verhältnissen bewirkt einen Zustand, der sich täglich nur verschlimmern kann. Ich bin daher entschlossen, noch ein Mittel zu versuchen, um dem Ärgsten vorzubeugen. Obschon ich an Geschäften, die bloss auf einen materiellen Vorteil abzielen, keinen Geschmack habe, so erfordert doch jetzt die Notwendigkeit, dass ich meine $\mathrm{Zu}-$ flucht dazu nehme. Ich will also meinem V[ater] vorschlagen, dass er mir erlauben soll, unter seiner Firma das Speditionsgeschäft, welches bis jetzt durchaus unbedeutend war, für meine Rechnung so stark wie möglich zu betreiben." Es ging mit diesem Plan nicht besser als mit dem früheren; am 20. Juli I 835 gesteht Hess, dass seine Hoffnungen für die nächste Zukunft vereitelt seien.

Zu den gescheiterten Plänen aus jenem Jahr gehören auch Hess' Heiratsabsichten. Am I I. Juni schreibt er in sein Tagebuch: „Es wurde dem Vater eine Heiratspartie für mich von und nach Bingen[?] angetragen, und da ich mit Zuntz überlegte, unter Bedingungen, die wahrscheinlich gebilligt werden, zu heiraten, so werde ich ohnedessen in einigen Wochen hinaufreisen." Am 20. Juni stellte es sich aber heraus, dass es mit der Partie nichts war, denn der in Aussicht genommene Schwiegervater verlangte $z u$ viel Geld von Hess. Auch aus einem anderen Heiratsantrag scheint nichts geworden zu sein, so dass Hess sich mit dem Gedanken trug, sich selbst direkt „per Einführung in ordentliche Familien" nach einer Gattin umzusehen. ${ }^{4}$ Er verlangte von seiner künftigen Frau, dass sie "unendlich liebend sein muss." 5 Schrecklich müsse es doch sein, „,wenn die ewige Begleiterin durch's Leben, statt dasselbe zu verschönern, es noch unerträglicher macht, als es in der Vereinzelung sein kann." 6

1 Ebenda fo Io-roa (20. Januar I 835 ).

2 Ebenda, fo I $2 a$.

3 Ebenda, fo 39.

4 Ebenda, fo 39 a.

5 Ebenda, fo 40.

6 Ebenda, fo 43 a. 
Hess machte öfters Ausflüge, sah sich die Maskenzüge im Karneval an, ging ins Theater und besuchte Kunstausstellungen. Sein Freundeskreis erweiterte sich um die Mitte der dreissiger Jahren. Zu seinen intimsten Freunden Zuntz und Levié, kamen neue hinzu. Über diese Bekannten und Freunde, die er öfters im Tagebuch nennt, lässt sich leider wenig sagen, da sie sich - mit zwei Ausnahmen: Heintich Kossmann und Andreas Gottschalk - nicht auszeichneten und in vollkommene Vergessenheit gerieten. Mit dem ersteren, den er in Bonn oder Köln kennen lernte und der später in Karlsruhe und in Heidelberg lehrte, stand er seit 1835 oder noch früher in brieflichem Verkehr. Die Korrespondenz scheint eingeschlafen zu sein, als Kossmann etwa August 1840 sich nach Russland begab, wo er als Lehrer der Mathematik und Physik in Petersburg wirkte und wo er sich auch den Titel eines russischen Hofrates erwarb. ${ }^{1}$ Mit dem künftigen Führer des Kölner Arbeitervereins, Andreas Gottschalk, ist er zwar noch nicht intim befreundet, kennt ihn aber schon im April $1835^{\circ}$

Da Zuntz der vertrauteste und treueste Freund von Hess war, ist es interessant zu erfahren, wie Hess selbst diese Freundschaft beurteilte. Was er über diese aussagt ist übrigens für seinen eigenen Charakter bezeichnend. Er gesteht in seinem Tagebuch (26. Juni I835), dass die Verschiedenheit der Natur und der Charaktere zuweilen eine Stimmung in seinem und seines Freundes Gemüte erzeuge, in der sie sich mehr abstossen als anziehen. Er glaube der Quelle solcher Antipathien auf die Spur gekommen zu sein. Von der Gesellschaft gesondert könne er zwar auf sich selbst zurückkommen, ja er ziehe sogar das einsame Leben dem gesellschaftlichen vor, allein sobald er ein Wesen habe, zu dem er sich schicklicherweise gesellen, das er lieben könne, so ordne sich bei ihm gleich „,das Einsamliche" dem "Gesellschaftlichen” unter. Er ziehe nicht die Zerstreuung der Reflexion vor, sondern er vertiefe seine Gedanken durch die Mitteilung, so wie er umgekehrt selbst wieder gerne der Mitteilung anderer ein williges Ohr leihe. Hierin nun unterscheide sich Zuntz wesentlich von ihm. Er sei Selbstdenker im strengsten Sinne des Wortes; er lebe in der Beschauung, in ihr allein; Unterhaltung sei ihm kein Bedürfnis. So wie er lieber unmittelbar von der Natur belehrt werde, als durch Vermittlung des Menschen, ebenso genüge ihm die Natur oder er sich selbst zum hehren Genuss der Wissenschatt. Er bekunde eine grössere Stärke des

1 Über Kossmann: Berthold Auerbach, Briefe an seinen Freund Jakob Auerbach. Ein biographisches Denkmal. Frankfurt a. M., 1884, 2 Bde, Bd. I, p. 26, 38 ; Kossmann an Berthold Auerbach, 27. Juli I840, unveröffentlichter Brief im Schiller-Nationalmuseum, Marbach; Hess, Tagebuch, passim.

2 Hess, Tagebuch, 23. April I835. Vgl. auch ebenda, Anfang März. 
Geistes, Hess selbst dagegen offenbare ein stärkeres Gefühl. Dieses Missverhältnis erzeuge indessen manches Übel. Hess hofft diesen Missstand in der Zukunft zu vermeiden, da er glaubt seine Quelle gefunden zu haben. Er könne, wie er selbst bekennt, nicht ohne Freund leben, und müsse sich deshalb Zuntz anpassen.

Die Tätigkeit im Kontor des Vaters konnte den geistig regen Hess nicht betriedigen. Er sehnte sich nach einer Möglichkeit seinen Geist freier zu entwickeln, und träumte von finanzieller Unabhängigkeit als Mittel zu diesem Zwecke. „Ich muss”, heisst es in seinem Tagebuch (7. Mai I 835), „zuerst mich frei machen in persönlicher Hinsicht (von meinem Vater), dann es dahin bringen, dass ich mich frei den Wissenschaften widmen kann." Man möchte glauben, dass er den Vorsatz hatte, Berufswissenschaftler zu werden. Soviel man aber den Andeutungen im Tagebuche ${ }^{1}$ entnehmen kann, wollte er sich nicht ausschliesslich der Wissenschaft hingeben; es darf eher angenommen werden, dass ihm eine vielseitige Bildung als ein Mittel erschien, welches ihm den Weg zur öffentlichen Tätigkeit ebnen sollte. Übrigens wirkte die Wissenschaft auf ihn auch wie eine Art Rausch. So schreibt er im Tagebuch (15. März I 835): „Der Gelehrtenstand ist meiner Individualität wohl so eigen, dass ich in der Nähe desselben nicht kaltblütig bleiben kann. Er gewährt mir einen übermässigen uneingeschränkten Genuss, worauf dann natürlich eine tödliche Leere folgt. Überhaupt hat mein Geist hier [in Köln] zu wenig Beschäftigung und verfällt daher sehr leicht in eine Lethargie."

Da Köln zu jener Zeit keine Universität hatte, suchte Hess geistige Anregung auf der Universität Bonn. Freilich konnte er dort nicht systematisch studieren, sondern nur gelegentlich einzelnen Vorlesungen beiwohnen. So hörte er einige Vorträge des Philosophiehistorikers Christian August Brandis, über Baco, Cartesius, Kant und spätere deutsche Philosophen; des Pädagogen und Philosophen Johann Friedrich Delbrück, über den Unterschied zwischen geistlicher und weltlicher Beredsamkeit; des Arztes Joseph Ennemoser, über Naturphilosophie; des Mediziners Mayer, über das menschliche Embrio; des Physikers Maschhof, über Magnetismus und Elektrizität; und einige andere nicht spezifizierte naturwissenschaftliche Vorträge. Er nahm auch Teil an einem Kolleg des Chirurgen Karl Wilhelm Wutzer und hatte dabei die Gelegenheit, wie er bemerkte, zum erstenmal einen vierzehn Tage alten Kadaver zu sehen und - zu riechen. ${ }^{2}$

Hess berichtet in seinem Tagebuch (6. Februar I 835) wie er sich seine freien Stunden einteilte: „des Morgens Latein, des Abends, nach dem

1 Ebenda, 21. März und 22. Juni 1835.

2 Ebenda, I 5 . und 21. März; 4. August; [Ende] September (fo 80a), I 835. 
Abendessen, Rechnen etc., dann Englisch, dann Geschichte, Lesen u.s.w.” Einige Monate später (13. Mai) führte er eine „,neue Tagesordnung” ein: ,abends Englisch, morgens Arithmetik, ein Tag Lektüre etc." Sein Tagebuch (1.I. I 835 - 22.I.1 836) hält uns über seine Lektüre auf dem laufenden. An Lehrbüchern benutzte er Heinrich Ludens „Geschichte der Völker und Staaten des Altertums”, Karl Hoffmanns "Grundlehren der Physik" und Johann Peter Müllers „Handbuch der Physiologie des Menschen”. Von historischen und publizistischen Arbeiten las er die Memoiren des Grafen von Ségur, Ferdinand Friedrich Buchholz' "Geschichte Napoleons Bonaparte”, Benjamin Constants "Mémoires sur les Cent Jours”, Victor Hugos „Etude sur Mirabeau” und Friedrich Georg von Raumers „Briefe aus Paris und Frankreich im Jahre I830". Auszüge machte er sich auch aus Jacob Böhmes „Werken” (Bd. I) und Fichtes „Ideen über Gott und Unsterblichkeit". Er las ferner Goethe, Schiller, Heine, Börne, Chateaubriand ("Atala”), Victor Hugo („Le dernier jour d'un condamné”), Ossian („Gedichte”) und Johannes von Müller („Briefe eines jungen Gelehrten"). Mit besonderer Vorliebe vertiefte er sich in Jean-Pauls Werke („Das heimliche Klagelied der jetzigen Männer und die wunderbare Gesellschaft in der Neujahrsnacht”, "Clavis Fichtiana seu Leibgeberiana”, „Vorschule der Âsthetik”, „Briefe an Friedrich Heinrich Jacobi"). So weit ging seine Bewunderung für den Dichter, dass auch er selbst, wie es in seinem Tagebuche (7. Juli i 835 ) heisst, manchmal "Jean-Paulisch" schreiben möchte. Von jüdischer Literatur erwähnt er nur Mendelssohns "Jerusalem, oder über religiöse Macht und Judentum". Fügt man dazu noch Eduard Jerrmanns Angriff auf die Kölner Sitten („Das Wespennest”, I 835) und Heintich Düntzers lokal-patriotische Antwort (,O-Jerum-Mann, oder der Seifenbläser. Abfertigung von Ed. Jerrmanns Schrift: das Wespennest", 1835), der Hess zustimmte, so erhält man eine beinahe vollständige Liste seiner Lektüre aus jener Zeit. Dazu kommen noch einige andere Bücher (wie z.B. ein Leben Spinozas), deren Verfasser oder Titel sich aus den Andeutungen in seinem Tagebuche nicht genau feststellen lassen. Zum Lesen merkte er sich noch vor: Josts „Geschichte der Juden", Lamennais' „Paroles d'un croyant" und Spinozas "Theologisch-politischer Traktat". ${ }^{1}$

Die meisten Äusserungen Hess' über die von ihm gelesenen Verfasser sind zu kurz und fragmentarisch um von grösserem biographischen Wert zu sein. Eine wichtige Ausnahme bilden seine Betrachtungen über Heine, dessen „Salon”(Bd. II: „Zur Geschichte der Religion und Philosophie in Deutschland") ihn tief beeindruckt hat.

1 Hess, Tagebuch, fo 3a, 17, 19a, 20a, 24a, 43, 44, 45a, 47, 50a, 54a, 57, 63a, 65a, 67, 68, 75, $8 \mathrm{r}, 83 \mathrm{a}, 88 \mathrm{a}, 89,99 \mathrm{a}, 103,103 \mathrm{a}, \mathrm{I}$ 1 7, I 20. 
Am I. Januar 1836 bezeugt er in seinem Tagebuch: „Es ist mir lieb, dass ich dieses Buch nicht früher zu Gesicht bekam, sonst weiss Gott, wie sich meine Ideen über unsere Zeit, die so sehr ähnlich mit denen Heines, aber in wesentlichen Punkten doch verschieden von ihnen sind, gestaltet hätten; jedenfalls behalte ich jetzt meine Selbständigkeit mehr, als wenn ich mir hätte eingestehen müssen, dass ich mir vor Heine meiner Ideen nicht klar bewusst bin. Fast eben so ging's mir mit Spinoza. Allein ich fühle jetzt erst recht das Bedürfnis, meine Ideen noch viel deutlicher auszubilden, dabei mich mit der neuern Philosophie und Theologie genau bekannt zu machen."

Heines Art zu schreiben erscheint Hess verführerisch und blendend, aber nicht überzeugend. Der grosse Dichter sei unstreitig ein Genie. Seine Zeit spiegele sich in ihm, aber nicht ihr bester Teil. Die frivolen Scherze Heines mit dem Heiligsten seien geeignet einzureissen aber nicht aufzubauen. Sein Spott über den ,alten Gott”, Jehova, erregten in Hess, der sich von dem Heine'schen Style nicht hinreissen liess, "wahren Ekel". Heine, meint Hess, habe übrigens seine Zeit, wie auch die Geschichte überhaupt, unrichtig gedeutet. Der „alte Gott” der Juden und Christen, behauptet Hess, sei kein andrer als der der Zukunft. Den von ihm selbst verehrten Spinoza habe der Dichter, wie es so oft geschehe, nur äusserlich, nicht in seiner „heiligsten” Bedeutung aufgefasst. Heine scheine Spinozas Grösse mehr zu ahnen als zu begreifen. Wenn es bei den Juden und Christen den Anschein habe, als ob sie von einem ausser ihnen sich befindlichen Gott regiert würden, so rühre dies nicht von der philosophischen sondern von der poetischen Seite der Religion her. Es würde aber nie eine Religion ohne Poesie geben. Die Philosophie sei die Grundlage der Religion; die Poesie das Gewand, in welches sie gehüllt erscheine. Die Religion sei die Identität von Philosophie und Poesie. Wehe den Völkern, wenn Philosophie und Religion sich feindlich entgegenstünden: das ganze Volk seufze alsdann wie in unserer Zeit nach Verjüngung. Diese könne aber nicht, wie Heine meinte, ,von aussen kommen, das Alte verdrängen und den leer gewordenen Platz einnehmen, sondern nur in sich selbst vorgehen. Wir leben noch unter demselben Himmel, aut derselben Erde der Alten, aber wir haben jetzt Winter und ein Frühling ist's, dem wir entgegengehen." 1

Heine wolle eher blenden als wirklich überzeugen. Seine schonungslose Verhöhnung des Philosophen Friedrich Heinrich Jacobi und seine verächtliche Geringschätzung des Mystikers Jacob Böhme stünden seinen sonstigen Spötteleien würdig zur Seite. Eine bilderreiche Sprache beweise aber nichts. Es sei der Phantasie leicht den

1 Hess, Tagebuch, fo I 14 -I I 4 a (2. Januar I 836 ). 
widersprechendsten Meinungen ein reizendes Gewand umzuhängen. Bilder sollten zwar zur Veranschaulichung gebraucht werden, aber man müsse sich davor hüten in den Fehler derer zu verfallen, die - wie Heine - glauben, die Wahrheit könne durch leichte Spiele errungen und befestigt werden. Gerade diesen Fehler kann Hess an Heine nicht genug tadeln. ${ }^{1}$ Hess ist aber tief gerührt über die Stelle, worin Heine die Getühle, die ihn bei der Lektüre Spinozas ergreifen, beschreibt. Heine spricht dort von den himmelhohen Gedanken Spinozas, von einem gewissen unerklärlichen Hauch in seinen Schriften, von dem Geist der hebräischen Propheten, der noch vielleicht auf ihrem späten Enkel ruhe, von seiner Gedankengrandezza, von seiner Märtyrerfamilie, und von dem Lebenswandel Spinozas, der frei von jedem Tadel sei und rein wie das Leben seines göttlichen Vetters, Christus. ${ }^{2}$ „An solchen Lichtpunkten", bemerkt Hess, „erkennen wir den besten Heine wieder, den genialen, prophetischen Heine." 3

In Hess' Ringen um eine Weltanschauung spielt das Gemüt eine nicht geringere Rolle als die Vernunft. Wo das Gemüt, meint Hess, mit den ewigen göttlichen Naturgesetzen übereinstimme, da herrsche Tugend. Diese könne man nicht wissenschaftlich lehren, denn wäre es auch dem Menschen möglich die ewigen Gesetze systematisch zu erfassen, so sei doch das Wissen allein unfähig das Gefühl zu erwecken und der Handlung den Trieb zu geben. Nun sei es aber auch nicht ratsam, die Moralgesetze der Willkür jedes Individuums preiszugeben. Es müsse also, nach Hess' Meinung, eine Lehre geben, die zwar wissenschaftlich begründet, aber nicht zum Verstande, sondern zum Herzen spreche. Eine solche Lehre sei die Religion. Gott als Lehrer werde in ihr vorausgesetzt. Als Urheber und Inbegriff aller Gesetze, spreche Gott zum Menschen in einer Sprache, die nur dem Gemüte, der Seele verständlich sei. Der Verstand möge prüfen und das Falsche scheiden, - nur das Leben gebe aber die Religion. Stets offenbare sich Gott den Menschen nach den Bedürfnissen der Zeit.4 „Es ist töricht, auf den Menschen durch Philosophie im positiven Sinne wirken zu wollen. Die ewigen Gesetze werden nur durch den erhabensten Enthusiasmus, durch einen Funken Gottes, im Menschen offenbar. Die Poesie ist der Elektrizitätsleiter, der ihn fortpflanzt, die Philosophie hat darüber zu wachen, dass sich kein unreines, irdisches Feuer einschleicht, denn wohl erkennt sie das Wahre, obschon nur in der Negation des Nichtwahren." 5

1 Ebenda, fo 116 und I 18 (2. und 3. Januar I 836).

2 Heine, Sämtliche Werke, ed. Elster, Bd. IV, 2 is.

3 Hess, Tagebuch, fo i i6a.

4 Ebenda, 1. Januar i 835 , fo 1 .

5 Ebenda, fo ra. 
Wer sich keine Philosophie geschaffen habe, bemerkt Hess, zweifle nicht selten an den höchsten Wahrheiten, an Gott, Tugend, Ewigkeit und Freiheit. Wahr sei aber, dass ein metaphysisches System dem Menschen so wenig den ewigen Frieden geben und sichern könne, wie die Bekanntschaft mit einer geometrischen Figur, oder das Wissen eines mathematischen Satzes. Das Bewusstsein allein könne nicht selig machen. Die Seligkeit sei eben erst die Identität von Bewusstsein und Handeln. All unser Handeln und all unser Wissen müsse in vollkommene Übereinstimmung gebracht werden. ${ }^{1}$

Selbstverständlich erscheint das Leben dem reiferen Hess viel verwickelter und schwieriger als dem Jüngling. So lesen wir in seinem Tagebuche (14. März I 835): „Ein herrlicher Morgen begrüsst mich! Er ruft schöne, stille Tage der Vergangenheit in mein Gemüt zurück, als ich mir ein idyllisches Leben träumte, als ich das wahre noch nicht kannte. Ach! Wissenschaft war meine einzige Leidenschaft; in Rousseau fand ich mein Ideal. - Was riss mich heraus aus dieser Blumenbahn? Erst die Liebe, und dann des Lebens Drang! Nun hat sich der Zauberflor gehoben; ich seh' die Welt in ihrer Wirklichkeit. Die Sehnsucht stiehlt sich wohl noch wie ehedem zuweilen in meinen Busen ein, allein die paradiesischen Bilder sind vor der rohen Wirklichkeit gewichen!"

Einige Monate später heisst es wieder in dem Tagebuche (16. August 1835): „Der Beruf des Mannes ist, die Weisheit zu erforschen, den Irrtum aufzudecken, die Bosheit zu entlarven, das Gute zu erkämpfen, mit Kraft, Mut und Ausdauer die Vollkommenheit nicht allein zu erstreben, sondern auch überall, wo ihm die Gelegenheit geboten ist, herzustellen."

Alles im Weltall, sagt Hess, müsse Gottes Zwecke notwendig erfüllen. Die Erkenntnis Gottes sei das höchste Ziel des menschlichen Strebens. Da der Mensch berufen sei, seine Seele oder Gott zu erkennen, und nach dieser Erkenntnis zu handeln, so unterscheidet Hess unter den Menschen, solche, die nach diesem Grundsatze leben, und solche, die es nicht tun. Und da die Bestimmung des Menschen sei, Gott zu erkennen, so werde derjenige, der seiner Bestimmung entspricht, „der reine Mensch”, wie ihn Hess nennt, je nach dem Grade seiner Einsichten, sich freiwillig den ewigen Gesetzen unterwerfen, während es „der unreine Mensch" gezwungen, blind, als totes Werkzeug tue. ${ }^{2}$

Schon 183 I hatte Hess, wie wir oben sahen, eine kritische Stellung

1 Ebenda, I4. Februar 1835, fo 17 a-1 8 .

2 Ebenda, 13. Oktober 1835 , fo $90-90 a$. 
dem orthodoxen Judentum gegenüber eingenommen. Im Laufe der nächsten Jahre erweiterte er seine Kritik auf das gegenwärtige Judentum überhaupt. Am I. Januar I835 schreibt er in sein Tagebuch: „Die mosaische Religion, als solche, ist abgestorben.” Alle Vorzüge, lesen wir an der gleichen Stelle, welche die jüdische Religion, an und für sich betrachtet, vor der christlichen habe, gereichten ihr gegenwärtig zu ebenso vielen Nachteilen. Sie habe einst mehr Leben gehabt als diese, aber der lebendige Organismus sei eben der Auflösung, dem Tode in der Zeit unterworfen. Ein Leichnam, auch wenn er einst das herrlichste Leben verkörpert habe, könne nicht lebendig und gesund, belebend und bessernd wirken. Die mosaische Gesetzgebung könne weder als solche die Juden binden, noch als Religion sie befriedigen; denn die Gesetzgebung sei nur im Staate bindend, die Religion aber müsse den Menschen überzeugen, das Gemüt befriedigen; allein, was könne der moderne Europäer für eine Religion fühlen, die auf eine gesellschaftliche Ordnung eingestellt sei, die weder in der Wirklichkeit bestehe, noch ein Ideal des Strebens für ihn darstelle? Es wird zwar versucht nachzuweisen, dass jene Gesetzgebung auf die Natur, die ewigen göttlichen Gesetze gegründet gewesen sei. Das sei löblich und nützlich, denn dadurch würden die verderblichen Vorurteile der Menschen entwurzelt und der Boden zu einer neuen Saat emptänglich gemacht. Doch das alles habe nichts mit Religion zu tun. Solle die Religion nicht direkt zum Herzen sprechen? Was helfe es den Juden, fragt Hess, dass ihre Religion die vollkommenste in ihrer Zeit gewesen sei? Wo erst nachgewiesen werden müsse, da höre die Herzenssprache auf, und das Reich der Philosophie beginne. ${ }^{1}$

Eine Offenbarung, die auf Verhältnisse Bezug habe, müsse mit diesen sterben. Die mosaische Offenbarung enthalte zeitliche und örtliche Wahtheiten, die in der Gegenwart nicht mehr wahr, also falsch, seien. Indem sie nur ihre eigenen Gesetze sanktioniere, schliesse sie die der Gegenwart aus. Die jüdischen Geistlichen setzten zwar ihre Tätigkeit kräftig fort, es werde ihnen aber nicht gelingen die mosaische Gesetzgebung zu erhalten, sondern nur den Geist der Bibel über die Menschheit $\mathrm{zu}$ verbreiten. Es sei jedoch wohl gleichgiltig, ob die Beschneidung oder die Taufe das allgemeine Vereinigungszeichen sei. Am besten wäre es, wenn alle diese, mehr trennenden als einigenden Symbole, durch den Geist ersetzt würden. ${ }^{2}$

Mit dem Untergang des Staatswesens, mit dem die jüdische Religion aufs engste vereinigt gewesen sei, habe auch diese eigentlich aufgehört zu bestehen. Man solle bedenken, bemerkt Hess am 30. September 1835, dass das, was sich seit der Zerstörung des Tempels bis zur

1 Hess, Tagebuch, fo $1 \mathrm{a}, 3,3 \mathrm{a}$.

2 Ebenda, fo 6a, 7. 
Gegenwart erhalten habe, „keine Religion, sondern nur eine Sebnsucht nach einem verlorenen und nie wiedergekehrten Gut war, und dass eben mit dieser kräftigen Sehnsucht alle Spuren des ehemaligen, eigentlichen Judentums aufhören werden und müssen. Diese Sehnsucht aber erhalten zu wollen, bloss damit das verstorbene Judentum im Gedächtnis bleibe, wäre ebenso barer Unsinn, als das Zurückrufen des vielgeliebten hingeschiedenen Vaters im Gedächtnis des Kindes. Schön ist gewiss die Trauer, die Sehnsucht nach dem entrissenen Vollkommenen - schön, human, wenn sie, wie alles menschliche in ihren natürlichen Schranken bleibt, aber ebenso, wie alles zu weit Getriebene, wird sie am Ende hässlich, widersinnig, lächerlich, ja, wie leider die Geschichte des Judentums in seinem Verfalle beweist, die Quelle zu allen Lastern!"

Hess' damalige Stellungnahme zum Judentum ist ambivalent. Einerseits äussert er sich liebevoll und mit einem kaum verhüllten Stolz über die Vergangenheit seines Volkes: „Es ist fast wunderbar," schreibt er, „wenn man bedenkt, wie das kleine Häuflein der Juden nur dazu bestimmt zu sein scheint, zu leiden und, gleichsam mit ihrem Märtyrertum, der Menschheit die verlorene Bahn der Unschuld wieder zu ebnen." 1 Andererseits scheint Hess vom Judentum abgestossen worden zu sein, da er glaubte es habe seine historische Rolle schon längst ausgespielt. Verliert ein Volk seine Daseinsberechtigung, so bleibt ja wenig mehr übrig, als sein Verschwinden zu wünschen oder zu empfehlen. Vor dieser Konsequenz schrickt aber Hess zurück. Deshalb erscheinen auch seine damaligen Ansichten über das Judentum unklar, verschwommen und schwerverständlich. Sucht man in seinem Tagebuche nach Anhaltspunkten zu einer Lösung der Judenfrage, so findet man mehr Kritisches als Positives.

Hess meint, die orthodoxen jüdischen Theologen, die steif und fest behaupten, man müsse zum Mosaismus zurückkehren, hätten nicht begriffen, dass das einmal Abgestorbene vergebens wieder zum Leben heraufbeschworen werde. Diesen Verblendeten, denen der gegenwärtige Zustand unbehaglich erscheine, sei der Seherblick in die Zukunft versagt. Deshalb suchten sie das Heil in einer längst, für immer dahingeschiedenen Vergangenheit. Das Rad der Geschichte lasse sich aber nicht in seinem Laufe aufhalten. ${ }^{2}$

Sei der alte Mosaismus lebensunfähig, so bleibe noch theoretisch die Möglichkeit die jüdische Religion durch eine Reform lebensfähig zu machen. Wie verhielt sich nun Hess zu dieser Möglichkeit? In einem undatierten, wohl etwa 1834 geschriebenen Manuskript,

1 Hess, Tagebuch, 2. Oktober 1835 , fo $84 a$.

${ }^{2}$ Ebenda, I3. Dezember 1835 , fo roga-106. 
„Betrachtungen über die Juden in Deutschland”, empfiehlt er eine „religiöse Verbesserung der Juden”, die nur durch wissenschaftlich gebildete Rabbiner durchgeführt werden könne. „Die Zeit ist da”, heisst es in diesem Manuskripte, „der jüdischen Theologie einen Stuhl neben den hohen Fakultäten unseres Vaterlandes zu errichten." Die dort gebildeten Rabbiner sollten auch als Schullehrer vom Staat besoldet werden. Eine natürliche, stufenweise und sichere Verbesserung des religiösen Lebens der Masse des jüdischen Volkes könne, nach Hess, nur durch solche Rabbiner stattfinden. Nun fragt es sich aber, welchen Zweck diese Verbesserung verfolgen sollte. Man würde nach einer klaren Antwort auf diese Frage vergeblich in dem Hess'schen Manuskripte suchen. Doch hat man beim Lesen dieses Manuskriptes den Eindruck, dass Hess bestrebt war, durch diese Verbesserung, die Juden zur Annahme des Christentums geistig und religiös vorzubereiten. Nur so, scheint es, kann die folgende Stelle im Manuskripte gedeutet werden: „Ob, wann die Kraft der Intelligenz das Gemüt der Juden durchdrungen, ihr religiöses Leben von allen politischen Schlacken, von allen den Irrtümern, die ihm von seinem Kindesalter noch ankleben, gereinigt haben wird, sie in dem Glauben ihrer Väter keine Befriedigung mehr finden, sich in Liebe mit ihren christlichen deutschen Brüdern vereinigen werden, müssen und können wir getrost der Zeit und dem inneren Werte der Kirchen überlassen. ${ }^{1}$ Was wir hingegen schon jetzt wissen, oder doch wenigstens nach so langer Erfahrung wissen sollten, ist, dass die Kinder der Furcbt und des Jammers [d.h. die Juden] ohne eine solche Läuterung nie fähig sein werden eine Religion der Liebe und der Freibeit [d.h. das Christentum] aufzunehmen, und dass Christus selbst, wenn er heute auf der Erde erschiene, kein andres Mittel, als diese Läuterung gebrauchen würde, um sie für seine Lehre zu gewinnen."

Wenn aber die „Verbesserung der Juden” eine Art jüdischer Vorschule für das Christentum bilden sollte, so darf man daraus noch nicht schliessen, dass Hess eine schnelle oder sogar eine bedingungslose Annahme des Christentums durch die Juden befürwortete.

„Das Christentum”, schrieb er, „,ist die Religion, die für die Gegenwart vollständig passt." (Tagebuch, I. Januar I 835). Das Judentum sei bestrebt gewesen eine Nation zu vereinigen, die Bestimmung des Christentums sei die Menschheit zu vereinigen. Das Reich der christlichen Religion sei die vereinigte Menschheit. Da aber das menschliche Geschlecht tatsächlich noch nicht vereinigt sei, so sei das Reich der christlichen Religion in der Gegenwart ein Ideal; allein die Hoffnung,

1 Eine ähnliche Stelle findet sich auch in einem anderen Hess'schen Manuskripte aus jener Zeit: „Die jüdische theologische Fakultät” (undatiert, Signatur: B 226). 
es zu realisieren, sei keine Schimäre. ${ }^{1}$ Nach der Annahme des Christentums durch die grossen Machthaber der Zeit, sei es unvermeidlich, dass sie es für weltliche Zwecke missbrauchten. Die Missstände, die daraus entstanden seien, hätten ihren Höhepunkt im i6. Jahrhundert erreicht. Der Reformation sei es jedoch gelungen, das Christentum von allen fremdartigen Schlacken zu reinigen, und es auf sich selbst zurückzuführen. ${ }^{2}$ Die christliche Religion habe auch eine Grundlage, die Person Christi, die solange positiv bestehen werde, bis überhaupt alle positive Religion überflüssig sei. $^{3}$ Warum eigentlich sollten sich dann die Juden nicht taufen lassen und auf diese Weise das Problem endgültig lösen? Hess, wie der Leser sogleich sehen wird, war dieser Lösung nicht grundsätzlich abgeneigt, obwohl er dagegen eine wichtige Einwendung anführte.

„Es gibt eine Ansicht”, sagt er, „nach welcher es kein Heil für die Juden gibt, solange sie nicht zum Christentum übertreten. Wenn wir auch, wie im Verlaufe gezeigt werden soll, diese Ansicht nicht so allgemein und unbedingt verwerten, wie es von der Gegenpartei geschieht, so bedarf's doch nur eines einzigen tichtigen Blickes in den gegenwärtigen Standpunkt der Juden, um die Unzulänglichkeit der Mittel, die gewöhnlich zu diesem Ende angewandt werden, einzusehen." 4 Bei den Juden müsse man zwei sich schroff entgegenstehende Hauptgruppen unterscheiden: die Orthodoxen und die Autgeklärten. $\mathrm{Da}$ die Orthodoxen für jede Aufklärung unzugänglich seien, so seien sie es noch viel mehr für jede Bekehrung; denn ihre Blindheit sei nicht die der Heiden, sondern beruhe auf der höchst naturwidrigen Stellung worin sie ein böses Geschick versetzt habe. Trümmer eines Volkes, das als Märtyrer der Menschheit in der Geschichte die erhabenste, wenn auch die tragischste Rolle spiele, seien sie am wenigsten geeignet durch irdische Lockungen sich zur Taufe bewegen zu lassen. Die wenigen Beispiele, die die Geschichte der Judenbekehrung aufzuweisen habe, zeigen, dass die Juden meistenteils nicht aus innerer Ưberzeugung sondern aus äussern Rücksichten zum Christentum übergetreten seien. Der Jude als solcher, der mehr oder weniger klar seinen Beruf erkenne, oder ihn schwächer oder stärker tühle, könne nicht zum Christentum übergehen, „solange dieses nicht, als wahre Weltreligion, jede trübende Beziehung von sich abwirft und rein und lediglich, seinem Stifter getreu, das Heil der Menschen, im ausgedehntesten, humansten Sinne, will." 5 In dieser Beziehung, meint

${ }^{1}$ Hess, Tagebuch, I. Januar 1835 , fo 7 .

2 Ebenda, 30. April I 839 , fo $332-34$.

3 Ebenda, 19. September 1835 , fo 81 .

4 Ebenda, 3. Oktober 1835, fo 852 .

5 Ebenda, fo 86. 
Hess, gebe es auch keinen Unterschied zwischen orthodoxen und aufgeklärten Juden. Auch der aufgeklärte Jude, wenn er bieder sei, frage sich, warum er die älteste, ehrwürdigste Religionsgemeinschaft verlassen solle und in eine neue treten, die doch nur das jüngere Kind der seinen sei. Wenn die christliche Religion, wie sie von sich rühme, besser und reiner als die seinige sei, ,warum wendet sie nicht humane Mittel an zum humanen Zweck? Warum überzeugt sie nicht, statt zu überreden und zu locken und zu drohen? Thr [Christen] fragt, was Ihr denn tun sollt - und das Mittel ist ja so einfach, so naheliegend." 1

Es ist klar, dass Hess bereit wäre, die Judenfrage durch die Taufe zu lösen, falls das Christentum seine eigenen Gebrechen überwinde und sich auf ein höheres Niveau emporhebe. Praktisch läuft aber seine Stellungnahme auf das Dilemma hinaus: beim Judentum bleiben, also einer überlebten Religion sinnlos weiter zu dienen; oder zum Christentum überzugehen, das zwar besser als das Judentum, aber für den Juden nicht gut genug ist, um von ihm in der Gegenwart angenommen zu werden. Hess suchte nach einem Ausweg aus diesem tragischen Zwiespalt, doch jahrelang wollte es ihm nicht gelingen einen solchen zu finden.

Einfacher erschien ihm das Problem der Judenemanzipation. Er wusste freilich, dass auch diese Frage nicht leicht zu lösen sei. Schrieb er doch, dass die Juden noch viele Kämpfe bestehen müssten, bis man sich ihrer als Menschen annehme. Oft werde man noch den Schwachen ihre Schwäche zum Vorwurfe machen, statt sie zu unterstützen. Bosheit und Dummheit würden noch vieles erdichten, bevor alle Dämone der Finsternis verschwinden würden. ${ }^{2}$ Trotzdem betrachtete er die Frage der Judenemanzipation als verhältnissmässig einfach, da es ja wesentlich „eine rein politische Frage" sei. ${ }^{3}$ Welche Hindernisse stehen der Emanzipation der Juden im Wege? fragt er im April i 835. Thre Religion und ihre Nationalität, lautet seine Antwort. Wahr sei, sagt er, dass das Christentum die Religion der neuern Zeit, der Mosaismus aber abgestorben sei. Daraus folge jedoch nicht, dass die Juden zur Emanzipation nicht berechtigt seien, denn in der Gegenwart sollten Kirche und Staat in ihrem eigenen Interesse vollkommen getrennt sein. Weder Kirche noch Staat hätten das Recht sich der politischen Gleichberechtigung der Juden zu widersetzen oder ihre Religion mit Gewalt zu zerstören. Beide müssten jedoch - Hess scheint hier in seinen eigenen Gedankengängen nicht ganz konsequent zu sein - sich bestreben den Mosaismus „durch Wahrheitsgründe dem

1 Ebenda, fo 86a.

2 Ebenda, 2. Oktober 1835 , fo $842-85$.

3 Ebenda, 28. Juli 1835 , fo 47 . 
Bedürfnis der Zeit gemäss umzuformen". ${ }^{1}$ Was mit dieser Umformung eigentlich gemeint ist, wird von Hess weder erklärt noch mit einem Worte angedeutet. Ungeklärt bleibt auch die Frage, wie die christliche Kirche und der von ihr getrennte Staat, die jüdische Religion umzuformen imstande seien. Was nun das zweite Hindernis anbelangt, das der Judenemanzipation im Wege stehe, die Nationalität, so meint Hess, dass neuere Staaten nicht mehr auf Nationalität gegründet seien. Seit der Staat nach einer hohen Einheit strebe, gebe es für ihn keine Frage der Abstammung der Bürger. Ständeabsonderung, Zunftsystem und Feudalsystem hätten aufgehört, und wenn der Staat seine Grundlagen kenne, so dürfe er auch die Juden, die in ihm wohnen, nicht im nationalen Sinne separieren. Der Staat dürfe den Juden nicht anders als einen anderen Bürger betrachten und behandeln. ${ }^{2}$

Steigendes Interesse wendet Hess seit I835 der sozialen Frage zu. Am 3. Juni 1835 notierte er in sein Tagebuch: ,Am Abend ging ich mit Herrmann [Levié] auf und ab, und teilte ihm meine Idee über eine bessere gesellschaftliche Ordnung, als die unsre ist, namentlich, was ich von der Nichterblichkeit halte, mit." Hess glaubte die Erblichkeit der Güter solle aufgehoben werden. Doch war er eine kurze Zeit über die Richtigkeit dieser Idee im Zweifel. Dies geht aus der Eintragung im Tagebuch vom Io. August 1835 hervor: „Ich hatte auch zu Bonn mit [meinem Freunde] Hirschland ein Gespräch über gesellschaftliche Einrichtung [en], wobei er die richtige Idee äusserte, dass die Gleichheit der Stände hergestellt und erhalten werden könne, ohne Aufhebung der Erblichkeit, vermittelst allgemeiner Assekuranzen." Obwohl nicht gesagt wird, worin diese "Assekuranzen" bestehen, so ist es klar, dass Hess diese Bemerkung nicht gemacht hätte, wäre er schon damals fest von der Notwendigkeit der Abschaffung der Erblichkeit überzeugt gewesen. Dass seine gesellschaftlichen Ideen rasch viel radikaler werden, wird man sogleich sehen.

Erwägungen über die französische Revolution führten Hess zu der Schlussfolgerung, dass diese Revolution nicht mit Napoleon beendigt sei. Das Buch der Revolution, um eine Metapher Victor Hugos ${ }^{3}$ zu benutzen, sei noch nicht voll geschrieben. "Noch ist weiter nichts geschehen," liest man in Hess' Tagebuch (10. Oktober I835), ,als hie und da der Erbadel und sein Schützling und Verbündeter, der alte Thron, erschüttert. Die Geldaristokratie wird ihn ganz umwerfen und sich einen neuen schaffen. Ob es Europa und seine Kolonien, ob es die heutige zivilisierte Welt noch weiter bringen wird?" Hier wird zwar

1 Ebenda, 6. April I 835 , fo 30.

2 Ebenda, fo 3 oa.

${ }^{3}$ Hugo, Etude sur Mirabeau, Paris, I 834, S. 90; Hess, Tagebuch, 10. Oktober I835. 
die Frage nur gestellt, doch zögerte Hess nicht lange mit der Antwort. Schon zwei Monate später schreibt er, dass in allen bisherigen Staatsgesellschaften ein Gift stecke, das die Quelle aller politischen Krankheiten war, ist und sein werde, solange es dieselben durchdringe. Keine Konstitutionen würden da helfen. „Alles Leben, jedes Streben muss endlich stocken, wenn das Aristokratengift alle Adern der Gesellschaft durchdringt. Ich meine nicht bloss die Adelsaristokratie, sondern hauptsächlich die Geldaristokratie. Ich meine jede Herrschaft, die nicht auf persönliches Verdienst gegründet ist, sondern sich auf das blinde Glück, auf das Vorrecht der Geburt beruft. Kurz ich meine jedes sogenannte bistorische Recht." (Tagebuch, I3. Dezember I 835). Wenn es auch Hess nicht einzuleuchten scheint, dass mit der Abschaffung der Erblichkeit, die sozialen und wirtschaftlichen Gegensätze bei weitem noch nicht aufgchoben seien, so bemerkt er doch an der gleichen Stelle: „Stets werden sich die Begünstigten und Benachteiligten feindlich entgegenstehen."

Als ob Reichtum ohne Erblichkeit überhaupt nicht bestehen könne, verzeichnet Hess in seinem Tagebuche (13. Dezember 1835): „Und nun naht die Zeit der Befreiung mit mächtigen Schritten. Denn ehe man sich's versieht, wird an einem frühen Morgen das ganze hochmütige Geschlecht, das stolz tut auf seine Erstgeburt, der ganze Adel, der ganze Reichtum, das ganze Recht der Erblichkeit vernichtet auf dem Boden gestreckt liegen. Zu spät werden nun den ewig Blinden die Augen aufgehen." Hess warnt die Kurzsichtigen, die nicht sehen, dass die französische Revolution nur das Vorspiel zu dem grossen Drama unserer Zeit gewesen sei (Tagebuch, 3. Januar 1836).

Er beginnt auch sein Erstlingswerk, „Die Heilige Geschichte der Menschheit", auszuarbeiten. Die Bedeutung dieses Werkes im Rahmen der Biographie des jungen Hess wird in einem folgenden Artikel untersucht werden. 